\title{
A CONTRIBUIÇÃO DO FUTEBOL FEMININO NA FAVELA DO MANDELA ANTE DA FALTA DE POLÍTICAS PÚBLICAS
}

\author{
THE FEMALE SOCCER CONTRIBUTION IN THE MANDELA'S FAVELA \\ IN THE LACK OF PUBLIC POLICIES
}

Rubens Teixeira Silva ${ }^{1}$

http://orcid.org/0000-0002-2998-6411 http://lattes.cnpq.br/2085086328907042

Recebido em 2 de junho de 2018

Aceito em 25 de novembro de 2019

RESUMO: O objetivo do presente trabalho é demonstrar como o futebol pode contribuir como uma ferramenta de política pública. Utilizou-se como objeto para este estudo a favela do manguinhos, no Rio de Janeiro. A região é cercada de um complexo de favelas, com 44051 moradores residentes, no total de 15 favelas. Os dados foram coletados através do projeto estrelas do Mandela, que tem atuado na região desde 2003, contribuindo com o desenvolvimento de jovens mulheres, com a diminuição da taxa de maternidade precoce, com a ocupação de crianças, adolescentes e jovens, não os deixando a disposição do tráfico de drogas. Este estudo reuniu informações tratadas através do método qualitativo, utilizou-se de uma pesquisa de campo tratada através da utilização de entrevistas e visitas ao projeto. Os resultados obtidos revelaram a promoção da capacidade dos jovens relacionados à interação com a sociedade, racismo, preconceito, sexualidade, drogas e qualidade de vida.

Palavras-chave: Política pública, desenvolvimento, pobreza e projetos sociais

ABSTRACT: The present study aim is to demonstrate how soccer can contribute as a tool of public policy. The Manguinho's favela, in Rio de Janeiro, was the object of this study. The region is surrounded by 15 shanty towns ("favela" in the local idiom), where 44051 people live. Data was collected through the Mandela's Stars Project, which has been in affectat in this place since 2003 and has helped young women by lowering the rate of precocious maternity. It has also kept children and teenagers away from drug trafficking by engaging them in sports activities. A qualitative method and a field research wereused in the gathering of information for this study wich consisted of interviews and visits. The results clearly showed anincrease in the skill of the youngsters involved in the project in fields related to citizenship, racism, sexuality, social prejudice, drug use and living Standards.

Keywords: Public policy, development, poverty and social projects.

\section{INTRODUÇÃO}

O cenário social das favelas no Rio de Janeiro demonstra ao longo dos anos abandono e falta de investimentos que promovam o desenvolvimento e manutenção do bem estar da população.Ao analisar-se o Estado, agente responsável em proporcionar condições para o

${ }^{1}$ Mestre em desenvolvimento local pelo centro universitário Augusto Motta - UNISUAM (2018). Possui MBA em gestão financeira, controladoria e auditoria pela universidade Castelo Branco (2014). Possui graduação de gestão em controladoria e recursos humanos pela UNIFOA (2008) e graduação em administração pela faculdade Gama e Souza (2012).e-mail:rubestrjrj@gmail.com 
desenvolvimento social, fica patente a insuficiência de políticas públicas. Essa insuficiência acarreta o empobrecimento da população e o agravamento dos problemas sociais.

Entretanto, são conhecidos os problemas sociais desde o Brasil colônia, sobretudo nas áreas menos favorecidas pelos interesses políticos. A favela do Manguinhos possui uma população total residente de 44051, a constituir um total de 15 favelas que englobam a região, com um índice de desenvolvimento social de 0,473 , ocupando a posição 150 , segundo levantamento do IPP (CAVALIERI; PERES, 2008).

Este cenário apenas evidencia a total falta de oportunidades econômicas e sociais na região. Nessas condições, restou a associação de moradores local promover a transformação deste cenário a partir da utilização do esporte para a promoção da satisfação social de crianças, jovens e adultos.

Entendeu-se que a prática regular de esportes contribuiria para a redução da taxa de maternidade das jovens, através do dialogo e disciplina, para o desenvolvimento da convivência social e comunicação, que resultaria em melhor apresentação na busca de emprego e para uma melhor qualidade de vida, decorrente da atividade dos jovens, ao e vitar, dessa forma, sua disponibilidade ao tráfico.

A oportunidade de propiciar uma melhor qualidade de vida associada à prática de esportes que não se limita apenas as mulheres, mas também a seus filhos e outros adolescentes, oferecendo-lhes possibilidades mais promissoras, tais como o ingresso em uma escola de futebol profissional. Observa que a atividade esportiva propicia outros resultados, como por exemplo, o exercício da disciplina, de regras de convivência social e da cidadania.

Ademais, observa-se também que a socialização destas pessoas apresenta-se como um desafio, que estimula os jovens a buscarem ingresso no mercado de trabalho ao possibilitarlhes melhor comunicação, apresentação pessoal e autoestima, neutralizando in justo estigma de favelados.

A proposta aqui apresentada teve como objetivo analisar a importância das políticas públicas, para ampliar a qualidade de vida da população de baixa renda na favela do Mandela.

\section{O CENÁRIO SOCIAL DE MANGUINHOS}

Para compreender a história de Manguinhos, torna-se necessário refletir sobre a história da cidade do Rio de Janeiro e das ações do Estado.A falta de concretização dos planos e projetos criados para a região bem como a negligência do Estado, contribuíram para o crescimento populacional desordenado de algumas regiões, dentre elas; a de Manguinhos, que se tornou um complexo de favelas (FERREIRA, 2003).

A região está contornada de problemas ambientais, é atravessada pelos rios faria-timbó e jacaré, que deságuam no canal do cunha, que se lança na baía de Guanabara, sendo um dos canais mais poluídos. Não obstante a poluição encontrada nos rios, como garrafas pet, sacolas plásticas e até mesmo peças de mobiliário, a região sofre constantes alagamentos devido a aterros que aconteceram na região da cidade universitária - local onde está localizada a Universidade Federal do Rio de Janeiro - UFRJ (BODSTEIN et al, 2004).

A região conhecida atualmente como Manguinhos está subdivididas em 15 áreas: conjunto residencial Nelson Mandela - mandela 1, comunidade Mandela de pedra, parque Carlos Chagas - varginha, conjunto habitacional Samora Machel - Mandela 2, condomínio nova CCPL, conjunto habitacional dos ex-combatentes, Tiradentes e Vila União, comunidade Vila 
Turismo, centro habitacional provisório II - CHP2, parque João Goulart, comunidade agrícola, parque Oswaldo Cruz - Amorim, comunidade vila São Pedro, condomínio embratel, condomínio DESUP e comunidade vitória de Manguinhos -CONAB. O crescimento desordenado ocorreu após transferências de empresas que ali estavam assentadas e a resultantes invasões de espaços abandonados na região, contribuindo para o avanço do número de comunidades (MARIA; GAMA, 2012).

Nesta localidade, reside a maior população de homens e mulheres de 30 a 50 anos, sendo o total de moradores do sexo masculino 8215 e do sexo feminino 8946. O total de crianças residentes na região de Manguinhos surpreende, sendo o total de 6329 crianças do sexo masculino de 0 a 14 anos e 625 o total de crianças do sexo feminino residentes em toda a região do manguinhos. A população de idosos acima de 60 anos parece baixa, se comparada com outras localidades; contudo devido à qualidade de vida oferecida nesta região, o total de idosos do sexo masculino é 1307 e do sexo feminino 1809. Para exemplificar melhor, segundo pesquisa demográfica do IBGE, 2010, demonstra-se na tabela 1, conforme abaixo, dados segundo total de domicílios visitados nas comunidades.

Tabela 1: Comunidades de manguinhos.

\begin{tabular}{lll} 
Comunidades & População & Domicílios \\
\hline Parque João Goulart & 3.758 & 950 \\
\hline Vila Turismo & 4.748 & 1.604 \\
\hline Chp-2 & 3.908 & 1.136 \\
\hline Parque Carlos Chagas & 1.152 & 353 \\
\hline Vila União (RA- São Cristóvão) & 994 & 324 \\
\hline Vila São Pedro & 1.003 & 330 \\
\hline Comunidade Agrícola de Higienópolis & 1.209 & 390 \\
\hline Parque Oswaldo Cruz & 4.776 & 1.232 \\
\hline Parque Herédia de Sá & 2.919 & 921 \\
\hline Parque Horácio Cardoso Franco & 742 & 244 \\
\hline Vila Arará & 5.119 & 1.567 \\
\hline Vitória de Manguinhos & 1.277 & 368 \\
\hline Conjuntos Ex-Combatentes e Suburbana & 1.389 & 463 \\
\hline Conjunto Nelson Mandela & 3.121 & 965 \\
\hline Conjunto Samora Machel & 3.188 & 985 \\
\hline Mandela de Pedra & 4.196 & 1.162 \\
\hline Total & 44.051 & 13.143 \\
\hline Fonte: & & $16 \mathrm{G}$ \\
\hline
\end{tabular}

Fonte: Instituto Pereira Passos, com base no censo demográfico do IBGE, 2010.

O nome dado a comunidade já revela características próprias desta região, conhecida como área de manguezal. Atualmente, esta característica é vedada por intenso aterramento ao longo do século por acumulo de lixo proveniente da cidade ou material de grandes obras de 
urbanização (FABIO et al 2005).

O bairro de Manguinhos, dentre os 161 bairros da cidade do Rio de Janeiro, encontra-se na $155^{a}$ posição no índice de desenvolvimento social, correspondendo a 0.518 a avaliação de desenvolvimento desta localidade. Faz-nos refletir sobre o que vem a ser a mobilização e a participação em contextos sociais complexos, marcados pela precariedade de serviços públicos, onde a violência se expressa na ausência de direitos afetando diretamente a vida dos moradores com a falta da saúde e infraestrutura (BRITO, 2003).

A rotulação existente sobre a principal via de acesso em Manguinhos, a avenida Leopoldo bulhões, tornou-se conhecida como a faixa de gaza, devido aos grandes conflitos ali existentes, conhecido como um dos redutos mais antigos e fortalecidos por facção criminosa de tráfico de drogas (ROBERTO, 2017).

Desta forma, tornou-se conhecida esta região, evidenciando vários registros de violência, morte, entre outros fatos rotineiros nas linhas do seu dia a dia.

\section{PROCESSOS METODOLÓGICOS}

$\mathrm{Na}$ realização deste artigo, foram utilizados dois tipos de pesquisa, uma pesquisa de campo e a qualitativa. Na primeira, foi desenvolvido um questionário, consultado junto auma das organizadoras do projeto, baseados em roteiros semi-estruturados aplicados pelo autor, visando conhecer todos os agentes que compõem o projeto.No questionário, objetivou-se medir as transformações e contribuições do projeto na comunidade local e a satisfação dos envolvidos.

A outra parte dos dados foi obtida por meio de uma pesquisa bibliográfica, coletadas em sites, revistas nacionais, publicações que abordassem temas sobre políticas publicas, desenvolvimento, pobreza e projetos sociais. A elaboração final deste artigo foi fruto do uso e da análise das informações coletadas nas fontes mencionadas. Elas serão usadas no sentido descritivo e no desenvolvimento de políticas públicas locais, resgatando expressões culturais e despertando os participantes para a prática do esporte e exercícios físicos.

\section{A CRIMINALIZAÇÃO DA POBREZA EM FACE DA FALTA DE DESEN- VOLVIMENTO EM FAVELAS CARIOCAS}

O Rio de Janeiro é a cidade com o maior número de residentes em favelas do país, conforme revela o censo 2010. São 1.393.314 pessoas nas 763 favelas na cidade do Rio de Janeiro (CAVALLIERI; VIAL, 2012).

A pobreza em algumas regiões está intimamente vinculada à falta de estruturas sociais e políticas públicas. Algumas áreas acabam sendo privilegiadas pelo poder público, motivados por atrair empresas para o local, o que pode contribuir para um investimento inicial. Não obstante, a questão da criminalização da pobreza é um processo histórico observado desde o Brasil colônia (ZALUAR; ALVITO, 2006).

Logo, o fato de se residir em áreas pobres acarreta uma série de transtornos. Observa-se a diferença de abordagem policial quando se comparam dois bairros da cidade do Rio de Janeiro: Copacabana, localizado da zona sul carioca, junto a orla das praias, que considera-se um bairro tradicional de classe média, e Manguinhos; um bairro da zona norte, constituído de favelas, bairro pobre. São numerosas as queixas sobre tal abordagem nas regiões mais pobres, ocasionada pela ligação automática estabelecida entre pobreza e marginalidade. A 
criminalidade e abordada diferente segundo o nível social, de forma que fundamenta-se critérios pré-estabelecidos para as regiões mais pobres. A criminalização se inicia quando se desqualifica as ações com falsas acusações (BRITO, 2017).

Segundo Kuhn; Silma (2016), a questão social não é senão a expressão do processo de formação e desenvolvimento da classe operária e de seu ingresso no cenário político da sociedade, exigindo seu reconhecimento como classe por parte do empresariado e do Estado.

Verifica-se então que, apesar do desenvolvimento em outras localidades, sempre haverá a favela a carecer do investimento de políticas públicas, que contribuam para que a sociedade enfrente enormes problemas sociais, como a marginalização, o tráfico, os assaltos, a quebra de patrimônio público etc (CAVALIERI; VIAL, 2012).

Da mesma forma, Coimbra (2001), menciona que desde o final do século XIX, as elites brasileiras construíram a noção da periculosidade, com o pensamento que o pobre, o negro, semi-alfabetizado, morador de periferia; poderia desenvolver mais fácil uma vocação para a criminalidade. Logo, pensa-se que o Estado torna-se um dos maiores responsáveis pela criminalização da pobreza na sociedade, não oferecendo serviços necessários de políticas públicas, executando preferivelmente o desenvolvimento para as áreas privilegiadas, o que aumenta ainda mais a desigualdade social, vezes a violar direitos e incapaz de contribuir para a real manutenção dos interesses da sociedade.

Vinod Thomas, diretor do Banco Mundial no Brasil sustenta que de todo dinheiro aplicado pelo governo federal em políticas sociais, apenas cerca de $20 \%$ chega aos mais pobres (BUSATTO, FEIJÓ, 2006).

Pensa-se na população pobre, negra, semi-alfabetizada, os moradores de favelas, contribuintes com manutenção do capitalismo. Noutra maneira, pode-se visualizar na prisão um objeto de ressocialização no olhar de uma classe dominante (COIMBRA, 2001).

$\mathrm{O}$ fato de associar violência aos que não possuem riqueza apresenta-se como um limitador do desenvolvimento de áreas carentes. De fato, alguns casos demonstram intolerância não contra o crime, mas contra quem a ele está associado, o pobre, a negligência a educação, a saúde e a moradia.

\section{A INTERAÇÃO ENTRE A COMUNIDADE E O PROJETO}

O time de futebol feminino estrelas do Mandela nasceu em 2003, inicialmente acontecia no conjunto habitacional Nelson Mandela, também conhecido como Mandela 1. No início do ano de 2006, os treinamentos passam a ser realizados no centro sócio esportivo Mandela 2, através da parceria na utilização do espaço com a associação de moradores do conjunto residencial Samora Machel, que iniciou a potencialização do projeto.

Dentre as variedades de projetos sociais existentes em comunidades de baixa renda, acredita-se que o futebol tem grande aceitação não só para os jovens do sexo masculino, mas também para os do sexo feminino. Quando se consideram as diferentes políticas públicas ou políticas sociais a atingir os pobres, encontram-se as de esporte e lazer, onde melhor atingem-se os objetivos (NAZARENO, 2017).

Segundo Souza (2006), as políticas públicas repercutem na economia e nas sociedades.Constatou-se que os fatores relacionados à cidadania que mais repercutem nas comunidades, estão interligados a fatores familiares e a educação. Um dos problemas evidenciados ao longo dos anos nas comunidades é a evasão escolar. O fato de haver conflitos armados e 
impedirem as crianças, adolescentes e jovens a exercerem o direito de ir e vir termina por prejudicar a capacidade de estudar.

A dificuldade de se relacionar em casa também é um problema para estes jovens. Uma família desestruturada, onde há constantes conflitos, contribuí para que alguns jovens se ausentem, ceda à tentação das drogas, vivam nas ruas ou mesmo iniciem suas próprias famílias ainda em uma fase muito precoce.

Segundo uma das executoras do projeto, durante os 12 anos de existência neste local, verificou-se o fato de jovens engravidarem muito cedo, sendo um motivo para se afastar do grupo. Em conseqüência, foi decidido agregar ao time de futebol estrelas do Mandela um novo público além das jogadoras, seus filhos. Algumas dessas crianças vinham para o treino em seus primeiros anos de vida, outros ainda de colo, promoviam a familiarização neste novo ambiente.

Segundo Souza (2006), definições de políticas públicas, mesmo as minimalistas, guiam o nosso olhar para o locus onde os embates em torno de interesses, preferências e idéias se desenvolvem.

Pensando-se na saúde emocional e social das jovens envolvidas que se tornam mulheres muito cedo, busca-se com as atividades ultrapassar várias desigualdades e necessidades relacionadas ao benefício da saúde e qualidade de vida (LENOIR; HASNI, 2004)

Nessas atividades se inclui um seminário chamado o papo com as minas, que visa dialogar sobre os temas ligados à saúde, gênero, raça, pluralidade cultural e esporte, a partir de sua própria vivência, onde todo histórico da iniciativa e representatividade local é fortalecido, estimulando a ajuda mútua.

O objetivo maior e contribuir para melhor comunicabilidade entre os jovens e suas famílias, evitando maior vulnerabilidade social ao promover maior integração familiar.

\section{O ESTABELECIMENTO DE PARCEIROS}

Para manutenção de um projeto social de participação gratuita, os desafios orçamentários são de fato obstáculo.

Apesar da necessidade de executar políticas públicas nas áreas carentes, precisa-se conseguir um subsídio financeiro para o andamento do projeto. Brito (2003) verificou que a desigualdade social é uma das consequências da má distribuição de renda, expressado pela pobreza, miséria, desemprego, violência, questão racial e de gênero.

Observou-se que uma das maiores dificuldades do time de futebol feminino é a falta de equipamentos esportivos (chuteira, meião, caneleira, etc) que garanta a integridade física das jogadoras. 
Grafico 1: Ciclo do projeto Estrelas do Mandela.

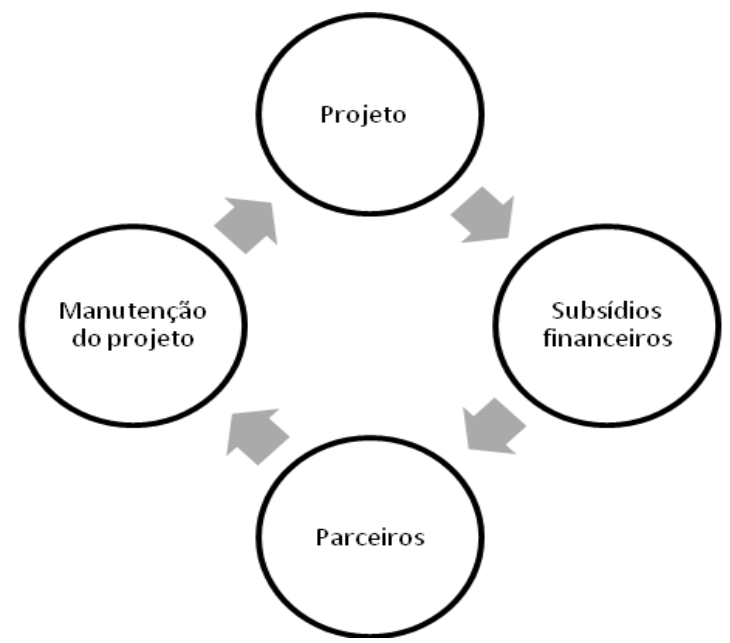

Fonte: Elaborado pelo autor.

A dificuldade de obtenção de recursos para equipamentos já resultou na cessação de atividades de vários outros projetos semelhantes no Rio de Janeiro. A necessidade de recursos financeiros é tão necessária quanto à obtenção de parceiros.

O projeto estrelas do Mandela se mantém graças a doações, além de subsídios financeiros obtidos através de programas da prefeitura, via edital. A parceria com instituições locais auxiliaram para que houvesse o espaço gratuito para prática de futebol, constituído de quadra e vestiários masculino e feminino, além de espaço para treinamentos e campanhas para captação de recursos.

A utilização de meios locais de comunicação como a agencia fala Manguinhos, o facebook e o jornal local auxiliam na promoção e divulgação do projeto.

A parceria com a Fundação Oswaldo Cruz (Fiocruz), que iniciou um trabalho de pesquisa com as participantes do grupo, introduzindo diálogos com o objetivo de veicular a importância da equipe de saúde da família na região, promovendo agendamentos de atendimentos básicos e necessários ao público feminino.

A casa da mulher de Manguinhos que também apóia o projeto com a realização de oficinas e rodas de conversas, demonstra a conveniência de estender as atividades às escolas públicas municipais do entorno.

A parceria com o centro universitário local, que disponibiliza profissionais de educação física, que supervisam treinamentos técnicos para melhor desempenho físico dos participantes.

\section{A CONTRIBUIÇÃO DO PROJETO NO PROCESSO DE FORMAÇÃO DO CARÁTER CIDẢDÃO E NO AUMENTO DA QUALIDADE DE VIDA}

A oportunidade de romper um paradigma sobre o futebol, que para muitos é um esporte masculino, propicia importantes benefícios colaterais ao agregamento que se inicia através do jogo.

A chance de influenciar comunidades vizinhas associa valores para as novas gerações, 
promove a interação social entre comunidades e contribui para uma oportunidade para melhoria da qualidade de vida de crianças, jovens e adultos. Além da diversão, a atividade traz satisfação e um sentimento de realização, fatores que facilitam o exercício da cidadania.

Segundo Luck (2017), a transformação ocorre através do desenvolvimento, com uma população proativa, saudável, competente e realizada.Quanto mais rica a vida associativa, menores serão as chances de pressão externa. Reconhecer o objetivo desta juventude que passa por este importante processo é uma das principais estratégias.

Neste sentido, objetiva o projeto o resgate histórico de Manguinhos, mobilizando a população, utilizando os mecanismos para fortalecimento da mudança social, com impacto direto na socialização e no reforço dos valores da cidadania e da igualdade dos direitos.

Para Souza (2006), do ponto de vista teórico-conceitual, a política pública em geral e a política social em particular são campos multidisciplinares, e seu foco está nas explicações sobre a natureza da política pública e seus processos.

Desta forma, o projeto ao longo dos anos vem conseguindo construir uma história e uma relação de parceria, coordenar um mapeamento social da região, desenvolver valores promovendo a formação de redes, arquitetando qualidade para as iniciativas culturais.

$\mathrm{Na}$ prática, que cada ação do projeto é planejada e executada visando a realidade local de crianças, adolescentes e jovens e do complexo de Manguinhos, a sociedade que existe e a que pretende-se construir.

O esporte, especialmente o futebol, é visto pelos moradores desses locais favelizados, como salvacionista, servindo como oportunidade para auxiliar na extinção de situações nocivas que assolam a região, como ocupações irregulares, ausência de políticas públicas e situações que obstaculizam a instalação de empresas e indústrias. Espera-se, através do projeto, criar empregos para a população local ao eliminar-se a falta de urbanização, a violência, e o preconceito.

Constata-se que os participantes do projeto desenvolvem maior tolerância e perseverança, se disciplinam e ao invés de se sentirem injustiçados, assumem uma atitude positiva ao promover a mudança do meio em que vivem.

Neste sentido convêm destacar a importância de projetos e metodologias que se mostram efetivos no sentido de pesquisar atividades dinâmicas, produzir reuniões para debates onde se aborde temas atuais, principalmente aquelas que aproximem famílias, jovens e instituições educacionais (RODRIGUES; GUARESCHI, 2009).

Verifica-se a contribuição do projeto com a diminuição da evasão escolar. Não obstante, proporcionando o desenvolvimento de crianças, adolescentes, jovens, homens e mulheres que de certa forma abandonaram o prazer pela prática do esporte, sendo pelo trabalho, pelos estudos ou devido outras circunstancias como a maternidade precoce.

Devido à promoção de jovens no campeonato da taça das favelas, verificou-se um aumento no numero de participantes e para a divulgação do projeto.

\section{CONCLUSÃO}

A região da favela do Manguinhos sofre como muitas outras áreas pobres na cidade do Rio de Janeiro, da carência de políticas públicas. Violência e urbanização desordenada agravou a desigualdade social na região, deixando mais patente o modelo urbano que historicamente caracteriza o Rio de Janeiro, que vulnerabiliza a maioria da população, ao ignorá-la 
como objeto de políticas publicas.Essa inação tem sido, entretanto, parcialmente mitigada por projetos como o acolhido por esta pesquisa. Tendo em vista os objetivos da pesquisa, considera-se que todos foram alcançados. Os resultados apontam para a diminuição da taxa de maternidade precoce, para jovens mais preparados para lidarem com a realidade do preconceito e racismo, para um melhor desempenho educacional, aumento da qualidade de vida e socialização.

Constatou-se que o problema da criminalidade existente nas áreas favelizadas, surge a partir da desigualdade estabelecida entre ricos e pobres, sendo esta desigualdade um fator determinante para a implementação de políticas públicas de qualidade que promovam o desenvolvimento.

Percebeu-se o estabelecimento de parceiros como diferencial para gestão e andamento do projeto, formando diretrizes, seja para tomada de decisão e processos administrativos, seja para auxilio nos programas de treinamento.

Ademais, observou-se que a prática de esportes, serviu como um apoio para as famílias, contribuindo para despertar a responsabilidade social de toda a comunidade.

O trabalho, contudo, se limita a questões de tempo, sendo necessários a continuidade e o acompanhamento do projeto.

\section{REFERÊNCIAS}

BODSTEIN, R., ZANCAN, L.; LEITÃO, C, R., et al. Avaliação da implantação do programa de desenvolvimento integrado em Manguinhos: impasses na formulação de uma agenda local.Revista ciência e saúde coletiva, v. 9, n. 3, p. 598, 2004.

BRITO, A.L. AImplantação de infra-estrutura de saneamento na região metropolitana do Rio de Janeiro: uma avaliação das ações do programa de despoluição da baía de guanabara. Revista brasileira de estudos urbanos e regionais,v. 5, n. 1, p. 6, 2003.

BRITO, M. V. Criminalização da pobreza e de defensores de direitos humanos. Cadernos do Ceas, n. 240, p. 238-255, 2017.

BUSATTO, C.; FEIJÓ, J. A era dos vagalumes: o florescer de uma nova cultura política. Canoas: Editora Ulbra, 2006.

CAVALIERI, F.; PERES, G. P. Índice de Desenvolvimento Social - IDS: comparando as realidades microurbanas da cidade do Rio de Janeiro. IPP: Rio de Janeiro, 2008.

; VIAL, A. Favelas na cidade do Rio de Janeiro: o quadro populacional com base no Censo 2010. IPP: Rio de Janeiro, 2012.

COIMBRA, C. M. B. Operação Rio: o mito das classes perigosas — um estudo sobre a violência urbana, a mídia impressa e os discursos de segurança pública. Niterói: Intertexto, 2001.

FABIO, F. P.; BODSTEIN, R., LEITÃO, C. R., et al.Lazer. Esporte e cultura na agenda local: a experiência de promoção da saúde em Manguinhos. Revista ciência e saúde coletiva,v. 10, n. 3, p. 767, 2005.

FERREIRA, R. S. Favela e os espaços monumentalizados: um lugar de memória coletiva e símbolo de resistência. Morpheus: Revista Eletrônica em Ciências Humanas, v. 2, n 3, p. 4, 2003.

KUHN, C.; SILMA, R. S. Criminalização da pobreza: Um estudo sobre a transformação do Estado social para o Estado penal. Emancipação, Ponta Grossa, v. 16, n. 2, p. 255-272, 2016.

LENOIR, Y.; HASNI, A. La interdisciplinaridade: por um matrimonio aberto de la razón, de la mano y del corazón. Revista Ibero-Americana de Educação, n.35, 2004.

LUCK, H. Gestão educacional: uma questão paradigmática. Vozes, Rio de Janeiro, 2017.

MARIA, T. F.; GAMA, R. R.C. As Comunidades de Manguinhos na História das favelas no Rio de Janeiro. Revista Tempo, v. 19, n. 34, 2012. 
NAZARENO, F. B. C. Educação cidadã pelo lazer: a contribuição das políticas públicas de esporte e lazer. Licere, v. 20, n. 1, 2017.

ROBERTO, R. S. A (Des)centralização da Política Nacional de Assistência Social no Contexto das Transformações Societárias.Trabalho apresentado no $5^{\circ}$ encontro internacional de política social $12^{\circ}$ encontro nacional de política social, Vitória, 2017.

RODRIGUES, L. C.; GUARESCHI, N. Políticas públicas e assistência social: diálogo com as práticas psicológicas. Vozes, Rio de Janeiro, 2009.

SOUZA, Celina. Políticas Públicas: uma revisão da literatura. Revista sociologias, n. 16, p. 20-45, 2006.

ZALUAR, A; ALVITO, M. Um século de favela. 5 ed. FGV: Rio de Janeiro, 2006. 